\title{
O TEATRO DO OPRIMIDO COMO RECURSO A UMA PRAXIS CIDADÃ
}

\author{
A. C. F. COSTA \\ Universidade do Estado de Minas Gerais \\ antoniocarlosfigueiredohist@gmail.com*
}

Artigo submetido em 17/02/2018 e aceito em 24/06/2019

DOI: $10.15628 /$ holos.2019.6948

\section{RESUMO}

A proposta do presente estudo é percorrer, em perspectiva histórica, a constituição do teatro sob o viés da política, tomando por origem a tradição ocidental a partir da antiga Grécia, e ressaltando, a grandes traços, a similitude existente entre essa forma de arte e o jogo de poder travado nas sociedades tempos afora, apontando para as perspectivas inerentes e a historicidade presentes em cada uma de suas poéticas. Por fim, procura desvelar o surgimento do Teatro do Oprimido, poética que prescreve a recuperação de um espaço cidadão que foi perdido em priscas eras. 0 corpus teórico formador do Teatro do Oprimido é composto por um conjunto de reflexões tributárias das obras de Erwin Piscator, Bertolt Brecht, da aplicação do método Stanislávski pelo Actor's Studio, bem como da experiência do Teatro de Arena. Entende-se que tratar das possibilidades de ação do Teatro do Oprimido se justifica tanto pela cristalina exequibilidade de sua execução, quanto pela adequabilidade de sua proposta no sentido de despertar consciências e inquirir acerca do momento oportuno para a sua adoção enquanto recurso cívico ao exercício de uma práxis cidadã de retomada dos espaços públicos, com vistas a reinscrever as demandas da base da população na agenda pública, em um contexto de luta por direitos sociais. A meta principal do Teatro do Oprimido é a libertação do ser humano das suas opressões, concomitantemente à uma busca constante da re-humanização das relações sociais.

PALAVRAS-CHAVE: Teatro do Oprimido, História do Teatro, Cidadania, Lutas sociais, Marxismo.

\section{THE THEATER OF THE OPRIMIDO AS A RESOURCE TO A CITIZEN PRAXIS}

\section{ABSTRACT}

The purpose of the present study is to look at the constitution of the theater under the political bias, taking the Western tradition as a starting point from ancient Greece, and to emphasize in great detail the similarity between this form of art and the game of power locked in societies throughout time, pointing to the inherent perspectives and historicity present in each of their poetics. Finally, it seeks to unveil the emergence of the Theater of the Oppressed, poetic that prescribes the recovery of a citizen space that was lost in priscas eras. The theoretical corpus that forms the Theater of the Oppressed is composed of a set of tributary reflections of the works of Erwin Piscator, Bertolt Brecht, of the application of the method Stanislavsky by
\end{abstract}

Actor's Studio, as well as the Arena Theater experience. It is understood that dealing with the possibilities of action of the Theater of the Oppressed is justified both by the crystalline feasibility of its execution and by the adequacy of its proposal in order to awaken consciences and inquire about the opportune moment for its adoption as a civic resource to the exercise of a citizen praxis of the resumption of public spaces, aiming to reinstate the demands of the population base on the public agenda, in a context of struggle for social rights. The main goal of the Theater of the Oppressed is the liberation of the human being from his oppressions, concomitantly to a constant search for the rehumanization of social relations.

KEYWORDS: Theater of the Oppressed, History of Theater, Citizenship, Social struggles, Marxism. 


\section{INTRODUÇÃO}

Ao curso das últimas décadas se formou uma espécie de tese apócrifa na sociedade, a qual baseada em um senso comum mal fundamentado, costuma atribuir integralmente à Escola, a tarefa de formar o cidadão. Assim, ao longo de um roteiro seriado de disciplinas, seria dever do aparelho escolar capitaneado pelo Estado, oferecer aos jovens a aparelhagem cultural necessária ao ingresso como partícipes ativos na vida da polis, tarefa que incluindo a esfera cabida ao homo faber, tenciona oferecer ainda ao estudante, a preparação para o mercado de trabalho.

Esse topoi que agrega a necessidade de uma educação de massa, aberta em tese portanto, a todos os jovens por intermédio da Escola pública, encontra em tempos de avanço neoliberal, um imenso entrave, ao condicionar o papel finalístico da Educação a uma entidade metafísica - o mercado - tornado espécie de panacéia remediadora de todas as demandas da sociedade. Dessa forma, junto àqueles que comungam do pensamento único, o mercado assume a forma de uma entidade metafísica, detentora de uma centelha mágica por força de sua "mão invisível" que seria capaz de uma auto-regulação de ajuste das necessidades humanas.

No entanto, toda essa espécie de mística alcandorada secretada através do discurso dos neoliberais, tem recebido fundamentadas críticas provenientes das lavras de respeitáveis estudiosos de variados quadrantes do espectro político, pesquisadores de elevada estatura intelectual, como István Mészaros (2005), Amado Luiz Cervo (2008) ou Thomas Piketty (2014). $\mathrm{Na}$ análise desses autores, e de vários outros, o diagnóstico sombrio revela o triunfo do monetarismo sobre o estruturalismo, tanto no pensamento quanto na práxis, com o Estado sendo afastado da indução do desenvolvimento, para ser transformado em uma espécie de gendarme dos interesses do capital.

Certamente os tomadores de decisão do capital transnacional discordariam dessas análises, tão ocupados em demonstrar pelo maquiamento de estatísticas ou pela prestidigitação de expectativas, o adequado funcionamento de um sistema operado mediante círculos tão viciosos de escassez e desperdício, e onde a bios política aparece tão invariavelmente contaminada pela promiscuidade entre esferas pública e privada - origem de tantos casos de corrupção - bem como pela interferência entre poderes constituídos, mediante a judicialização de questões que seriam propriamente políticas.

Face à percepção dessa conjuntura política de avanço dos interesses do capital e ataque aos direitos sociais e às liberdades democráticas, os quais conforme é sabido, foram conquistados sob o crisol de tantas lutas, esse trabalho foi formulado. O cerne das nossas intenções se nutre da conviç̧ão que, mesmo diante de uma conjuntura tão adversa, não podemos abrir mão de apresentar a jovens e adultos, o patrimônio cultural da humanidade, o qual não pode se tornar uma herança monopolizada por alguns poucos tocados pela fortuna.

Dessa forma, elegemos algumas ideias que gravitam por um amplo instrumental 
teórico que entende o Estado em sua forma ampliada, como presente nos escritos de Antonio Gramsci, que percebe o homem como ser omnidimensional, conforme defendido por Marx e Engels, e que classifica a Educação não em formato reducionista, de uma mera integração ao mercado de trabalho, mas sob uma pedagogia de inspiração freiriana, que exigindo respeito aos saberes dos educandos, é também crítica, e que se encontra mediada pelo compartilhamento de experiências, e não pela competição.

Assim, cabe ressaltar alguns pressupostos que gravitam pelo imenso instrumental teórico da plêiade intelectual que acima nominamos, os quais convergem para a constatação de que a universalização da educação entendida em sentido latu, deve caminhar pari passu com a universalização do trabalho, e que ambos, educação e trabalho, devem consistir em atividades humanas auto-realizadoras, conforme defendeu Meszáros (2005).

Sendo assim, cumpre estabelecer as condições do que Karl Marx, em obra de sua mocidade - os Manuscritos econômicos e filosóficos - qualificou como a libertação completa do ser humano, que iria muito além da preocupação com a base material e econômica, mas da liberação da sua consciência e do seu inconsciente. Partindo dessa constatação, Antonio Gramsci formulou a sua compreensão de práxis - conceito de elevada importância epistemológica ao problema que apresentamos - ampliando a noção original de Marx, de domínio do homem sobre a natureza, para definir a práxis como o fazer-se da História, ou seja, a sua realização por obra da vontade racional.

Integrando o universo dessas escolhas, cabe ressaltar que, para Antonio Gramsci, cabe ao proletariado instaurar o processo que leve à superação da cultura burguesa, luta que confundese com a disputa pela hegemonia, e onde avulta a força representada pela sociedade civil, e de aparelhos dessa, como a Igreja, os sindicatos e as escolas.

Face a essas condições, a pedagogia e a estética do oprimido parecem completar-se, pois no mesmo movimento no qual o homem, face a essa pedagogia, descobrindo a palavra, descobre-se enquanto homem (FREIRE, 1978), possibilita a que em uma segunda oportunidade, seja ampliada a sua capacidade de tornar-se sujeito de todo o processo histórico, dadas as possibilidades abertas pela estética do oprimido, da qual o Teatro do Oprimido, conforme estamos considerando, reúne as condições para apresentar-se como uma das suas mais plenas realizações.

\section{O TEATRO E A POLÍTICA}

O Teatro do Oprimido é uma poética de inspiração marxista, e que busca retomar o espaço cedido, em tempos primevos, ao controle da classe dominante. Por tratar-se de proposta inserida em uma concepção artística marxista, cabe ressaltar que, para os marxistas, não se pode entender o presente sem um determinado passado, tornado agente vivo na plasmação do presente, e por meio deste, condicionando o futuro, motivo pelo qual, o passado não desaparece como um todo, persistindo enquanto força ativa no presente. Dessa forma, em consonância com 
a estética inerente ao Teatro do Oprimido, cabe ter presentes algumas ideias manifestadas pelos marxistas acerca da arte, conforme escreveu Leandro Konder. Assim, para esse autor,

a aquisição, ampliação e transmissão da autoconsciência humana conseguidas nas grandes realizações artísticas não fazem senão manifestar esse poder de persistência do passado. A durabilidade do conhecimento artístico decorre da interação dialética de passado, presente e futuro.(KONDER, 1967, p. 228).

Com efeito, para que possamos apreciar com maior abrangência o cerne das mudanças contidas na proposta formulada pelo Teatro do Oprimido, cabe recorrer à história do teatro, que em priscas eras na Grécia, era parte componente do manancial de educação cívica popular, passando posteriormente a ser integrante curricular na formação da aristocracia ateniense especialmente, sobretudo na era clássica. Antes disso porém, cumpre tomar contato com algumas proposições que partiram da lavra do historiador neerlandês Johan Huizinga, o qual defendia ser o teatro uma espécie de jogo, tendo portanto seu surgimento em um solo lúdico, sine qua non ao surgimento da cultura e formação da civilização.

Huizinga caracterizou as formas de arte - tais como o teatro - na qualidade de atividades lúdicas desenvolvidas pela espécie humana, identificando no jogo que a este se encontra imbricado, uma das grandes atividades arquetípicas desenvolvidas pelo homem na sua formação civilizacional. Cabe esclarecer que para Huizinga, ao lado do jogo, encontram-se enquanto atividades arquetípicas a linguagem, o mito e o culto, e que "por detrás de toda expressão abstrata se oculta uma metáfora, e toda metáfora é jogo de palavras. Assim, ao dar expressão à vida, o homem cria um outro mundo, um mundo poético, ao lado do da natureza." (HUIZINGA, 2010, p. 7).

Cabe observar com esse autor que desde as sociedades primitivas, os homens celebraram seus ritos sagrados, com "seus sacrifícios, consagrações e mistérios, destinados a assegurarem a tranqüilidade do mundo, dentro de um espírito de puro jogo, tomando-se aqui o verdadeiro sentido da palavra" (HUIZINGA, 2010, p.7). Conforme observou Huizinga, foi no mito e no culto que tiveram origem as grandes forças instintivas da vida civilizada, tais como o direito, a ordem, o comércio, o lucro, a indústria, a arte, a poesia, a sabedoria e a ciência, às quais, ainda segundo o autor, possuem suas raízes no solo primevo do jogo.

Conforme observa Huizinga, essa idéia que liga o jogo à civilização não é algo novo, pois ao início da Idade Moderna ainda era geralmente aceita, embora em sentido limitado. Isso significa que o elemento lúdico da civilização, nos decisivos passos de afirmação do sistema capitalista, já não era claramente reconhecido. Cabe acrescer com esse autor que, ao início do século XVII, quando se deu o surgimento do grande teatro laico, com Shakespeare, Calderón e Racine, era o teatro que então dominava a literatura ocidental, e o costume era comparar o mundo a um palco, onde cada homem desempenhava um determinado papel. $O$ autor compreende que esse costume de comparar o mundo a um palco seria efeito de certo eco do neoplatonismo então dominante, sob "um tom moralista fortemente acentuado" (HUIZINGA, 2010, p. 8). 
Ora, é justamente em consideração a esse tom moralista que cabe aqui tecer maiores explicações para que consigamos prosseguir, tarefa que nos coloca frente à poética de Aristóteles. Façamos recurso à uma obra clássica de Arnold Hauser (1982). Conforme esse autor, a Atenas clássica - aprox. 508 a 322 a.C - não era tão rigidamente democrática conforme às vezes o senso comum pode supor.

Ao longo do processo de formação da democracia ateniense, valeria dizer, das instituições democráticas básicas, a nobreza tornou-se plutocrática, perdendo paulatinamente a sua antiga unidade e consistência. Assim, mesmo sendo governada em nome do povo, a Atenas do século $\checkmark$ seria uma cidadela da aristocracia, somente parecendo democrática quando comparada ao despotismo oriental. Uma comprovação disso seria que homens como Milcíades, Temístocles e Péricles pertenciam a famílias da antiga nobreza. Poetas e filósofos como Píndaro, Ésquilo, Heráclito, Parmênides, Empênides, Empédocles, Heródoto e Tucídides, e até os comediógrafos - cultores de uma arte que afinal seria essencialmente democrática - eram aristocratas, alguns cabe dizer se não de origem, por visão de mundo, e colocavam-se ao lado da aristocracia e da reação, da mesma forma que plebeus como Sófocles e Platão, não integrantes da nobreza, identificavam-se com essa. As exceções, escreveu Hauser, ficavam por conta dos sofistas e de Eurípedes.

Aliás, Eurípedes - autor de peças como Medeia, Electra ou As Troianas - foi severamente criticado por Aristófanes, que o acusou de corroer velhos ideais éticos da aristocracia, bem como os antigos cânones idealistas da arte. Aristóteles, em sua poética, e citando Sófocles, entendia que Aristófanes retratara os homens como deviam ser, ao passo que Eurípedes os havia retratado tais como eram.

De acordo com Hauser, partisse de Sófocles, de Aristófanes ou de Aristóteles, o estilo clássico ou ainda, a arte clássica seriam representativas de um mundo melhor, mais normativo e composto por seres eticamente superiores. Observa Hauser que esse ponto de vista caracterizava uma visão de mundo aristocrática, que prevalecia na época clássica e revelou-se decisiva na escolha dos assuntos a serem representados. Dessa forma, a tragédia veio a tornarse, na opinião de Arnold Hauser,

a criação de arte mais característica da democracia ateniense, e em nenhuma outra forma de arte se discernem, tão direta e tão claramente como nela, os conflitos internos da sua estrutura social. Os aspectos externos da sua apresentação às massas eram democráticos, mas o seu conteúdo, as sagas heróicas, com o seu ponto de vista trágico-heróico, era aristocrático. A princípio a tragédia dirige-se a um auditório mais numeroso e variado do que o constituído pelas assembléias de pessoas de posição à mesa das quais se recitavam as baladas heróicas ou as epopéias; e por outro lado, faz a propaganda do homem generoso e grande, do invulgar homem eminente, corporização do ideal de kalokagathia. Tinha a sua origem na desintegração do condutor do coro do próprio coro, que transformava a execução de canções em diálogo dramático - separação que, por si só, marca uma alteração no sentido do individualismo; mas a tragédia, para alcançar o seu efeito, depende da existência de certa consciência de comunidade no auditório e da possibilidade de ser apreciada por vastas massas do mesmo nível: na realidade, só pode alcançar pleno êxito, quando constitua uma experiência de massas. Somente, o próprio auditório da tragédia grega é ainda, em certa medida, um auditório seleto, consistindo, no melhor dos casos, de cidadãos livres, e não é 
mais democrático no seu conjunto do que as classes que governam a cidade. (HAUSER, 1982, p. 124).

Com efeito, o espírito a orientar o teatro oficial seria ainda menos popular que o seu público, o qual aliás, não exercia qualquer influência na escolha das peças encenadas, bem como nos prêmios que ocasionalmente a essas eram atribuídos. Pois tais escolhas ficavam nas mãos dos cidadãos ricos, aos quais cabia arcar com os custos das representações, ao passo que a atribuição de prêmios era tarefa de representantes do conselho, decisão que colocava em primeiro lugar as considerações de ordem pública. Dessa forma, a entrada gratuita no teatro, bem como as compensações em dinheiro pelo tempo nele gasto, serviam como fatores de inibição das massas para exercer qualquer influência nos destinos dessas encenações, fatores que podemos inferir, seguindo ainda a Hauser que, um teatro sob tais parâmetros não era um teatro do povo, conforme tentaram crer os românticos.

O teatro ático como expressão de teatro democrático seria então uma falsificação histórica, e conforme esse autor explica, os teóricos clássicos e românticos alemães somente o tenham recepcionado como um teatro do povo por terem visto em sua expressão uma instituição de caráter educativo. Aliás, é sob essa premissa que o teatro aparece nos compêndios voltados à História da Educação, seja em autores mais antigos, como Henri-Irénée Marrou (1969) ou Francisco Larroyo (1974), passando por Mario Alighiero Manacorda (1996), e chegando a Franco Cambi (1999). De acordo com esse último, a atividade teatral, juntamente com os jogos agonísticos ou ginásticos, ligados a festividades religiosas, desenvolviam "uma função educativa no âmbito da polis, acompanhando a ação das leis e sublinhando seus fundamentos éticoantropológicos, como ainda o caráter de livre vínculo coletivo."(CAMBI, 1999, p. 79).

Para Arnold Hauser (1982), o verdadeiro teatro do povo teria sido a farsa mimada, a qual resultara de uma evolução muito mais longa e contínua que o chamado teatro oficial, e que não era subvencionada pelo Estado, não recebendo, portanto, diretivas do poder constituído, atendendo não obstante, em seus princípios artísticos, a experiência imediata que provinha do contato com o público. Nessa forma de teatro, as cenas eram naturalistas e curtas, esquemáticas - portanto, não haviam dramas estruturados compostos por personagens heróico-trágicos de origem nobre e ações sublimes - mas a vida cotidiana mais trivial, conectada aos gostos populares e ao seu bom senso. Afinal, o objetivo da farsa mimada não era instruir, mas distrair o público. Conforme explica Hauser, os mímicos - atores da farsa mimada - podiam até ser atores profissionais, mas mantiveram-se populares, ao menos enquanto a farsa mimada não se tornou moda.

Conforme observou Arnold Hauser, a produção teatral que compunha a farsa mimada que não era tão somente muito mais antiga que a tragédia, mas ligada às danças mágicosimbólicas, ritos de colheita, magia da caça e culto dos mortos - foi quase totalmente perdida. A tragédia grega ao contrário, provinha de uma forma de arte não dramática - o ditirambo - e foi provavelmente buscar a sua feição dramática - cabe dizer com o autor, da transformação de atores em personagens fictícias e transposição do passado épico ao presente - à forma mimada. A tragédia, definitivamente se propunha a atingir outros fins aquém da mera distração do 
público, com o elemento dramático sempre subordinado ao elemento lírico e didático, além obviamente do efeito dramático do coro.

Assim, na avaliação de Hauser,

No seu teatro-festival tinha a cidade o seu mais valioso instrumento de propaganda, e certamente jamais pensaria em permitir que o poeta dela fizesse o que o gosto lhe ditasse. Os trágicos são, na realidade, negocistas e fornecedores do Estado: o Estado paga-lhes as peças que se representam, mas, naturalmente, não autoriza a representação das que forem contra a sua política ou contra os interesses das classes dominantes. (HAUSER, 1982, p. 126).

Assim, ainda na antiguidade grega, por força da classe dominante, foram erguidas no teatro, três imposições, às quais Augusto Boal (1975, p.123) entendeu assemelharem-se a barreiras ou paredes, que seriam: 1. A apropriação do teatro pelas classes dominantes, ocasião na qual o canto ditirâmbico executado pelo povo, ao ar livre, foi encerrado sob divisórias, instituído sob um espaço determinado, sob o controle e patrocínio dos donos do poder; 2 . A separação entre atores e público, doravante espectadores; 3. A separação de um ator do coro, o qual ocupará o protagonismo na cena teatral. Tais mudanças foram então endossadas sob a autoridade de Aristóteles, com o seu sistema coercitivo trágico canonizado enquanto poesia épica, de tragédia e de comédia, por força dos livros que restaram da sua obra Poética (ARISTÓTELES, 1996).

Essa forma de teatro, identificado a grosso modo como tradicional, afinou-se posteriormente com uma poética burguesa, tendo sido atualizado nos tempos modernos pela poética idealista de Hegel, após contribuições de autores como Nicolau Maquiavel e da dramaturgia shakesperiana. Cabe acrescer que os homens do lluminismo, na segunda metade do século XVIII, trataram de construir a quarta parede entre a ação teatral e o público. Teria cabido ao filósofo enciclopedista Denis Diderot a originalidade da sugestão, em virtude do Discurso sobre a poesia dramática, ensaio que veio a lume em 1758. Assim, no capítulo XI, denominado Do interesse, Diderot tomou da pena para escrever o seguinte trecho, que vale reproduzir,

quer compondo, quer representando, fazei de conta que o espectador não existe e não penseis nele em nenhum dos casos. Imaginai no proscênio uma grande parede que vos separa da platéia e representai como se a cortina estivesse aberta. (DIDEROT, 1986, p. 78-79).

Essa maneira de entender o processo criativo, bem como da forma pela qual seus resultados acabam recepcionados pelo público ao qual é dirigido, fundamentaram de certa forma, as conclusões a que chegou Karl Marx, quando falou da hostilidade mantida pelo capitalismo em relação à arte. De acordo com Afonso Sánchez Vázquez (1968), o que Marx teria deixado claro é que, na sociedade capitalista haveria uma contradição radical entre esse 
sistema e o homem enquanto ser criador, isto é, ressaltando-se as peculiaridades do trabalho artístico como domínio da qualidade e do originário, valeria dizer, como lócus de uma criação que é especificamente humana, forma de labor que estaria interdita em sua integralidade, bem como quaisquer dos seus resultados acessórios sobrestados, face às características intrínsecas ao sistema capitalista.

Ao início do século XX, a proposta contida no teatro dialético de Bertolt Brecht ofereceu uma ruptura em relação ao sistema coercitivo aristotélico. Nesse sistema, o espectador delegava poderes ao personagem para atuar e pensar em seu lugar. Assim, a proposta do sistema aristotélico era a catarse, onde cabia aos espectadores purificar-se de sua falha trágica, o que significa dizer, de algo que deseja, que pense e que possa ser capaz de transformar a sociedade na qual vive. Em contraposição a esse sistema, Bertolt Brecht acenou com uma poética marxista, cuja proposta é a conscientização. Na poética de Brecht, o mundo se revela como transformável, e a transformação segundo esse autor, começa no teatro, já que o espectador não delegou poderes ao personagem para atuar em seu lugar. A experiência nessa proposta se revela ao nível da consciência, mas não da ação. Assim, cabe à ação dramática esclarecer a ação real, mas o espetáculo apresenta-se como uma mera preparação para a ação.

De certa forma, o Teatro do Oprimido é uma proposta que busca resgatar o teatro de volta ao povo, como em remotas eras, onde, conforme dito linhas acima, significava o canto ditirâmbico, com a população cantando ao ar livre em diversas polis gregas da antiguidade, antes das classes dominantes apropriarem-se do teatro.

O Teatro do Oprimido ocupa papel de relevo na obra teórica de Augusto Boal, o qual foi inspirado entre outros, por autores como Stanislavski, Brecht e John Gassner, este último seu professor na Universidade de Colúmbia, Nova York (VIANA, 2016, p. 78). A proposta do Teatro do Oprimido é que o espectador volte a representar, atuando a partir do teatro e prosseguindo enquanto sujeito ativo nas lutas coletivas do seu cotidiano, seja ele proletário ou não.

O segundo passo do Teatro do Oprimido consiste em romper com o sistema de propriedade privada dos personagens, pela instituição do Sistema Coringa, o qual pode intempestivamente substituir a qualquer dos atores, resultado de uma metodologia de trabalho surgida em meio às atividades do Teatro de Arena, na década dos anos de 1960, em uma conjuntura que podemos caracterizar como de grande efervescência, embates políticos, mas sobretudo, de uma imensa criatividade. Lembremos que foi a época na qual nasceram os Centros Populares de Cultura da UNE, onde a cultura popular era associada à consciência revolucionária, somente justificada então como forma de ação sobre a realidade social (ARANTES, 1982, p. 54$55)$.

\section{CONSIDERAÇÕES FINAIS}

Este estudo teve, como tema central, a apresentação da poética do Teatro do Oprimido, bem como a assertividade de utilização de seus métodos, em uma conjuntura identificada pelo avanço das propostas de cunho neoliberal, em momento de globalização assimétrica e agressiva em várias circunstâncias à própria soberania de várias nações, sobretudo nos países periféricos. 
Nesse contexto o Teatro do Oprimido é apresentado como estratégia de conscientização política, tanto da classe trabalhadora, quanto de grupos socialmente estigmatizados e vulnerabilizados, como negros, índios, mulheres ou LGBT's.

O Teatro do Oprimido revolucionou o cenário das artes no Brasil, ganhando repercussão internacional na esteira da sua evolução. Convém assinalar que a sutil combinação de uma sofisticada inspiração teórica - Piscator, Brecht, Stanislavski, Actors Studio (N.Y.) - associada aos exíguos recursos mobilizados para a sua execução - contribuição recebida do Teatro de Arena tornaram possível seu sucesso, não somente na América Latina, mas também em países de culturas e formações sociais tão diferentes, como a Índia, ou os Estados Unidos da América do Norte, além de diversas nacionalidades do continente africano.

A sua proposta consiste em oferecer um método teatral cujo objetivo é o exercício do pensamento político, social e estético dos oprimidos, estimulando com isso, a busca de uma sociedade livre de opressores. A proposta do Teatro do Oprimido não é a catarse, como no sistema teatral aristotélico, nem a conscientização, como na poética brechtiana, mas a própria ação na sociedade. Colocadas essas diferenças básicas entre as três poéticas acima citadas, cumpre reiterar que o Teatro do Oprimido busca oferecer a ruptura com as marcas deletérias que ineludivelmente foram se acumulando nas vidas pregressas dos cidadãos, desde o ambiente escolar, demorando-se vida afora nos percursos do mundo do trabalho, resultando em substanciais mudanças na própria forma de entender o exercício da cidadania.

Caberia ainda ressaltar que na filosofia do teatro do oprimido tais marcas do passado não devem ser esquecidas, mas superadas, para que o presente, e as suas realidades possam vir a ser mudadas. A metodologia de trabalho do Teatro do Oprimido, como ocorre em praticamente todas as formas de teatro ocidentais, se dá através dos jogos e exercícios, exemplificados tanto nos escritos de Augusto Boal (1975 e 2011), quanto em obra da lavra de Dimir Viana (2016). Tais exercícios intentam oferecer as condições necessárias ao início da prática teatral propriamente dita, à qual pode encontrar sua condição de execução nas escolas, sindicatos, associações comunitárias, presídios, ou qualquer ambiente onde se faça necessária a re-humanização do homo faber, com vistas à sua reintegração no universo da polis, enquanto sujeito de agenciamento.

\section{REFERÊNCIAS BIBLIOGRÁFICAS}

ARANTES, Antonio Augusto. O que é cultura popular. 3.ed. São Paulo: Brasiliense, 1982.

ARISTÓTELES. Poética. In: . São Paulo: Nova Cultural, 1996, p. 27-60.

. Ética a Nicômaco. In: São Paulo: Nova Cultural, 1996, p. 117-320.

BOAL, Augusto. Teatro do oprimido: e outras poéticas políticas. Rio de Janeiro: Civilização Brasileira, 1975.

A estética do oprimido: reflexões errantes sobre o pensamento do ponto de vista estético e não científico. Rio de Janeiro: Garamond, 2009. 
. Jogos para atores e não-atores. Rio de Janeiro: Civilização Brasileira, 2011.

BRECHT, Bertolt. Teatro dialético. Rio de Janeiro: Civilização Brasileira, 1967.

CAMBI, Franco. História da Pedagogia. São Paulo: Unesp, 1999.

CAMPOS, Cláudia de Arruda. Zumbi, Tiradentes: e outras histórias contadas pelo Teatro de Arena de São Paulo. São Paulo: Perspectiva, 1988.

CERVO, Amado Luiz Cervo. Inserção internacional: formação dos conceitos brasileiros. São Paulo: Saraiva, 2008.

DIAS, Edmundo Fernandes. Cultura, política e cidadania na produção gramsciana de 1914 a 1918. Cadernos do CEDES. V.3: Educação e política: Gramsci e o problema da hegemonia. Campinas, 1983, p. $31-56$.

DIDEROT, Denis. Discurso sobre a poesia dramática. São Paulo: Brasiliense, 1986.

. Pedagogia do oprimido. 6.ed. Rio de Janeiro: Paz e Terra, 1978.

HAUSER, Arnold. História social da literatura e da arte. T.1. 4.ed. São Paulo: Mestre Jou, 1982.

HUIZINGA, Johan. Homo ludens: o jogo como elemento da cultura. 6.ed. São Paulo: Perspectiva, 2010.

KONDER, Leandro. Os marxistas e a arte: breve estudo histórico-crítico de algumas tendências da estética marxista. Rio de Janeiro: Civilização Brasileira, 1967.

LARROYO, Francisco. História Geral da Pedagogia.T.1.São Paulo: Mestre Jou, 1974.

MANACORDA, Mario Alighiero. História da Educação: da Antiguidade aos nossos dias. 5.ed. São Paulo: Cortez, 1996.

MARROU, Henri-Irénée. História da Educação na Antiguidade. São Paulo: Herder, 1969.

MÉSZAROS, István. A educação para além do capital. São Paulo: Boitempo, 2005.

PAMPLONA, Marco Antonio Villela. A questão escolar e a hegemonia como relação pedagógica.

Cadernos do CEDES. V.3: Educação e política: Gramsci e o problema da hegemonia. Campinas, 1983, p. $2-30$.

PIKETTY, Thomas. O capital no século XXI. Rio de Janeiro: Intrínseca, 2014.

PISCATOR, Erwin. Teatro político. Rio de Janeiro: Civilização Brasileira, 1968.

VÁZQUEZ, Adolfo Sánchez. As idéias estéticas de Marx. Rio de Janeiro: Paz e Terra, 1968.

VIANA, Dimir. Teatro do oprimido na educação de jovens e adultos. Curitiba: Appris, 2016. 
